\title{
PERBANDINGAN TINGKAT KESEJAHTERAAN RUMAH TANGGA PENYADAP DI PERKEBUNAN KARET YANG BERJARAK DEKAT DAN JAUH DARI PERKOTAAN
}

\author{
Comparison of Tapper Household Welfare in Rubber Enterprises \\ within Near and Far from the City
}

\author{
Iif Rahmat FAUZI ${ }^{1}$, Ernita BUKIT ${ }^{1}$, Erwin PANE $^{2}$, Abdul RAHMAN ${ }^{2}$, \\ dan Tumpal H.S. SIREGAR ${ }^{1}$
}

${ }^{1}$ Balai Penelitian Sungei Putih, Pusat Penelitian Karet

PO BOX 1415 Medan 20001 Sumatera Utara

Email : iifrahmatfauzi@gmail.com

${ }^{2}$ Universitas Medan Area. Program Pasca Sarjana.

Jl. Setia Budi No. 79-B Medan 20120 Sumatera Utara

Diterima : 9 Februari 2015 / Direvisi : 18 Mei 2015 / Disetujui : 15 Juli 2015

\begin{abstract}
Along with the decreasing of rubber price, tappers welfare issues has become a problem for rubber enterprises. This research aimed to study the issue of tappers welfare in two categories of rubber enterprises. The research was conducted through a survey method with two categories of companies, namely the company whose plantations were located close to the town (PB A) or provincial capital and the company whose plantations were located far away from the town or provincial capital (PB B). Sample was selected on purpose according to the company category. The results showed that the welfare level in the $P B A$ was better than that of $P B B$, but the low of tapper welfare for both of them had not touched on the level of insecured food. Limited access to have education or school, to business center and trade, and to government service centers, could be the reason to recommended that plantation management would initiate to provide facilities to cover those needs as well as other main needs self or through cooperative scheme.
\end{abstract}

Keyword: Hevea brasiliensis, tapper, welfare, two type of rubber enterprises

\footnotetext{
Abstrak

Seiring dengan melemahnya harga karet, isu mengenai kesejahteraan rumahtangga penyadap menjadi masalah tersendiri bagi perusahaan perkebunan karet. Penelitian bertujuan mengkaji isu kesejahteraan rumahtangga penyadap pada dua kategori perkebunan karet. Penelitian dilakukan melalui metode survei dengan dua kategori perusahaan, yaitu perusahaan perkebunan dengan lokasi kebun berada dekat dengan ibu kota provinsi dan perusahaan perkebunan dengan lokasi kebun
}

berada jauh dari ibu kota provinsi. Sampel ditentukan secara sengaja sesuai dengan kategori perusahaan. Hasil penelitian menunjukkan bahwa tingkat kesejahteraan rumah tangga penyadap di kebun kota dapat dikategorikan lebih baik dari rumah tangga penyadap di kebun terpencil, namun rendahnya kesejahteraan rumah tangga penyadap di kedua kebun belum menyentuh level kerawanan pangan. Keterbatasan akses memperoleh layanan pendidikan, usaha dan perdagangan, dan layanan pemerintah menjadi alasan agar menejemen perusahaan mampu menyediakan fasilitas untuk memenuhi kebutuhannya sendiri atau melalui mekanisme fungsi koperasi.

Kata kunci: Hevea brasiliensis, penyadap, kesejahteraan, dua tipe perkebunan karet.

\section{PENDAHULUAN}

Aspek penyadapan merupakan faktor yang sangat penting dalam aktivitas budidaya tanaman karet, karena menyerap biaya sebesar 45 - 50\% dari biaya produksi dan menentukan umur ekonomi tanaman karet. Secara umum masalah yang dihadapi oleh perusahaan perkebunan karet saat ini adalah mutu sadap yang cenderung menurun, serta semakin sulitnya merekrut angkatan kerja produktif dan terampil untuk menjadi tenaga penyadap (Santoso dan Basuki, 1991: Siregar et al., 1984).

Di negara-negara pertanian dengan pendapatan rendah, penggunaan tenaga kerja dilakukan secara intensif, namun produktivitas marginal tenaga kerja 
cenderung rendah, padahal upah tenaga kerja perkebunan umumnya jauh lebih tinggi. Selain dalam bentuk uang perusahaan juga menyediakan fasilitas lain seperti perumahan, jasa-jasa, kesehatan, dan fasilitas pendidikan bagi para karyawannya. Sehingga dalam hal biaya, tenaga kerja termasuk bagian terbesar dari pengeluaran total untuk semua kategori perkebunan (Spillane, 1989).

Salah satu tindakan yang dilakukan oleh perusahaan perkebunan untuk mengatasi kerugian dalam aktivitas budidaya tanaman perkebunannya adalah dengan melakukan efisiensi faktor-faktor produksi. Faktor-faktor produksi yang dimaksud salah satunya adalah tenaga kerja itu sendiri (Ravianto, 1985). Gejala tersebut secara umum dialami oleh perusahaan perkebunan karet saat ini yang dalam beberapa tahun terakhir terus tertekan oleh kecenderungan harga karet yang terus menurun. Kekhawatiran akan semakin rendahnya tingkat kesejahteraan keluarga penyadap menjadi masalah tersendiri, sebab aspek kesejahteraan sangat menentukan preferensi angkatan kerja terhadap profesi penyadap.

Indikator utama kesejahteraan masyarakat dapat dilihat dari tingkat ketahanan pangan. Ketahanan pangan diartikan sebagai terjaminnya akses pangan bagi setiap individu masyarakat untuk memenuhi kebutuhan pangannya. Sejarah membuktikan bahwa ketahanan pangan sangat erat kaitannya dengan ketahanan sosial, stabilitas ekonomi, stabilitas politik dan keamanan atau ketahanan nasional. Dalam arti jika dalam suatu negara terjadi masalah ketahanan pangan maka kestabilan ekonomi, politik dan sosial akan terguncang (Suryana, 2001; Simatupang et al., 2001), maka demikian halnya dalam lingkup perusahaan perkebunan karet. Penelitian ini bertujuan mengkaji sejauh mana tingkat kesejahteraan rumah tangga penyadap di perkebunan karet.

\section{METODE PENELITIAN}

\section{Lokasi Penelitian}

Penelitian dilakukan di Sumatera Utara dan Riau pada tahun 2014. Lokasi penelitian ditentukan secara purposive sampling berdasarkan dua kategori perkebunan, yaitu kebun di dekat kota dan kebun terpencil yang lokasinya berada relatif jauh dari perkotaan. Masing-masing kategori diambil satu kebun sampel. Lokasi kebun yang di dekat kota sangat strategis yaitu terletak di jalan utama dan hanya berkisar $30-50 \mathrm{~km}$ dari ibukota provinsi, sedangkan kebun yang terpencil lokasinya terisolasi, jauh dari ibukota provinsi, dan dari jalan utama.

\section{Metode Pengambilan Sampel}

Pengumpulan data di kebun dilakukan dengan mewawancarai penyadap menggunakan daftar isian (kuesioner). Peubah yang diamati antara lain latar belakang afiliasi responden terhadap pekerjaan penyadap, umur, pendidikan, masa kerja, jumlah tanggungan keluarga, jumlah anggota keluarga usia kerja, pemilikan asset, total pendapatan dan pengeluaran rumahtangga. Disamping itu dilakukan diskusi dengan Kepala Kebun, Asisten Afdeling, dan Mandor Sadap. Metode dasar yang digunakan adalah metode diskriptif yaitu penelitian yang memusatkan diri pada pemecahan masalah aktual yang didapat pada masa sekarang (Singarimbun dan Effendi, 1995). Responden dipilih dengan metode penarikan contoh acak sederhana yaitu $20 \%$ dari populasi penyadap yang dianggap mewakili (Tabel 1).

\section{Teknik Pengumpulan Data dan Macam Data}

Teknik pengumpulan data dan informasi dilakukan dengan cara wawancara langsung menggunakan kuesioner, pencatatan, dan observasi. Jenis data yang dibutuhkan adalah data dan informasi dari penyadap dan pihak manajemen perkebunan. Selain itu diperlukan data dari instansi terkait yaitu Badan Pusat Statistik (BPS) mengenai data kependudukan dan ketenagakerjaan. Data yang diamati meliputi data primer dan sekunder.

\section{HASIL DAN PEMBAHASAN}

\section{Kondisi Umum}

Kebun A (PB A) adalah kebun sampel yang mewakili lokasi kebun yang berada 
Tabel 1. Jumlah responden penyadap

Table 1. Number of tappers as respondence

\begin{tabular}{cccc}
\hline \multirow{2}{*}{$\begin{array}{c}\text { Perkebunan } \\
\text { Estate }\end{array}$} & \multicolumn{3}{c}{$\begin{array}{c}\text { Jumlah responden (orang) } \\
\text { Number of respondance (person) }\end{array}$} \\
\cline { 2 - 4 } & KHT & KHL & Total \\
\hline Perkebunan Karet & 13 & 6 & 19 \\
PB B & 12 & 24 & 36 \\
\hline Sumber : data primer yang diolah, 2014 & &
\end{tabular}

relatif dekat dengan kota. Sementara kebun B (PB B) adalah kebun sampel yang mewakili lokasi kebun yang berada jauh dari kota (terpencil). Jarak PB A ke kota diperkirakan sejauh $45 \mathrm{~km}$, sementara jarak PB B ke kota diperkirakan sejauh $100 \mathrm{~km}$. Untuk menuju PB A dibutuhkan waktu hanya sekitar 30-45 menit dari kota terdekat melalui jalur darat, sementara untuk menuju PB B dibutuhkan waktu sekitar 2-3 jam dari kota terdekat.

Kegiatan penyadapan secara umum dilakukan oleh Karyawan Harian Tetap (KHT), Karyawan Harian Lepas (KHL). Pada PB A, tenaga penyadap memiliki komposisi $18,5 \%$ orang KHT dan $81,5 \%$ orang KHL. Pada PB B, tenaga penyadap memiliki komposisi 34,5\% KHT dan 65,5\% KHL. Rasio tenaga penyadap dengan luas tanaman menghasilkan (TM) pada PB A adalah sebesar 3,2 ha/penyadap, sementara pada PB B sebesar 5,8 ha/penyadap. Tingginya rasio luas areal TM dengan jumlah tenaga penyadap di $\mathrm{PB}$ B menunjukkan adanya masalah ketersediaan tenaga penyadap.

Usia tenaga penyadap di PB A untuk KHT berkisar antara $32-53$ (44) tahun dan untuk KHL berkisar antara $24-54$ (38) tahun, dengan lama kerja masing-masing sekitar 14 dan 8 tahun. Sementara di PB B, usia tenaga penyadap KHT berkisar antara $28-41$ (34) tahun dan KHL berkisar antara 23 - 53 (34) tahun dengan lama kerja masing-masing 4 dan 3,5 tahun. Tenaga penyadap pada $\mathrm{PB} B$ memperlihatkan keragaan usia yang lebih muda dengan lama kerja yang lebih singkat. Dengan usia perkebunan yang relatif sama, kondisi di atas mengindikasikan tingkat keluar masuk (turn over) tenaga kerja yang tinggi di PB B. Tingginya rasio areal dan jumlah penyadap serta turnover penyadap memberikan sinyal adanya perbedaan tingkat kepuasan penyadap terhadap perusahaan masingmasing.

Di PB A, sebanyak 83\% responden penyadap KHT dan $69 \%$ responden penyadap KHL menyatakan memiliki pekerjaan sampingan. Di PB B, sebanyak $25 \%$ responden penyadap KHT dan $4 \%$ responden penyadap KHL menyatakan memiliki pekerjaan sampingan. Sejumlah penyadap memiliki pekerjaan sampingan disebabkan jam kerja harian yang secara

Tabel 2. Rasio luas TM dengan jumlah penyadap (ha/penyadap)

Table 2. Ratio of mature area and tappers (ha/tappers)

\begin{tabular}{|c|c|c|c|c|}
\hline \multirow[t]{2}{*}{$\begin{array}{c}\text { Perkebunan } \\
\text { Estates }\end{array}$} & \multicolumn{3}{|c|}{$\begin{array}{l}\text { Status penyadap } \\
\text { Tapper's status }\end{array}$} & \multirow{2}{*}{$\begin{array}{c}\text { Rasio } \\
\text { (Luas TM/penyadap) } \\
\text { Ratio } \\
\text { (Mature area/tapper) }\end{array}$} \\
\hline & $\begin{array}{c}\mathrm{KHT} \\
P D L \\
\text { [orang } \\
(\%)]\end{array}$ & $\begin{array}{c}\text { KHL } \\
\text { UPDL } \\
\text { [orang } \\
(\%)]\end{array}$ & $\begin{array}{l}\text { Total } \\
\text { [orang } \\
(\%)]\end{array}$ & \\
\hline PB A & $13(19)$ & $57(81)$ & 70 & $225,31 / 70=3,20$ \\
\hline PB B & $20(34)$ & $38(66)$ & 58 & $339,13 / 58=5,80$ \\
\hline
\end{tabular}

KHT $=$ Karyawan Harian Tetap $(P D L=$ Permanent Daily Labour $)$

$\mathrm{KHL}=$ Karyawan Harian Lepas $(U P D L=$ Unpermanent Daily Labour $)$

Angka dalam kurung menunjukkan persentase terhadap total

Figures in brackets are percentage of the total 
umum berakhir sekitar Pukul 13.00 - 14.00, sehingga banyak waktu luang yang masih dapat dimanfaatkan untuk kegiatan produktif lainnya. Di PB A, pekerjaan sampingan yang umum dilakukan oleh penyadap yaitu berladang, memelihara ternak, buruh borongan, dan berjualan. Sementara di PB B, secara umum pekerjaan sampingan yang dilakukan oleh penyadap adalah buruh borongan. Tingginya peluang memperoleh pekerjaan sampingan di PB A merupakan sebab tingginya rasio tenaga KHL di perusahaan tersebut.

Dari segi tingkat pendidikan, di PB A memperlihatkan sebanyak $54 \%$ tenaga penyadap KHT dan 32\% tenaga penyadap KHL hanya tamatan $\mathrm{SD}, 46 \%$ tenaga penyadap KHT dan 24\% tenaga penyadap KHL tamatan SMP, serta 0\% tenaga penyadap KHT dan 44\% tenaga penyadap KHL adalah tamatan SMA (Tabel 3). Sementara PB B memperlihatkan 20\% tenaga penyadap KHT dan $57 \%$ tenaga penyadap KHL hanya tamatan $\mathrm{SD}, 50 \%$ tenaga penyadap KHT dan $32 \%$ tenaga penyadap KHL tamatan SMP, serta 30\% tenaga penyadap KHT dan $11 \%$ tenaga penyadap KHL adalah tamatan SMA. Jika dikaitkan dengan lama kerja penyadap maka kecenderungan tingkat pendidikan penyadap KHT yang rendah di PB A disebabkan karena sebagian besar penyadap tersebut merupakan tenaga kerja lama yang telah memasuki usia pensiun, dimana untuk mendapatkan status KHT pada masanya relatif tidak membutuhkan persyaratan yang sulit, cukup tamatan SD dan terampil menyadap. Berbeda halnya ketika persyaratan kerja yang dewasa ini menuntut seorang KHT tidak hanya terampil menyadap tetapi juga memiliki pendidikan akhir SMP atau bahkan SMA sebagai akibat dari meningkatnya angkatan kerja yang berpendidikan tinggi.

\section{Tingkat Kesejahteraan Penyadap}

Dalam mengukur tingkat kesejahteraan masyarakat, Badan Pusat Statistik (2011) menggunakan delapan indikator, yaitu : kependudukan, kesehatan, gizi, pendidikan, konsumsi rumah tangga, ketenaga-kerjaan, perumahan dan

Tabel 3. Karakteristik penyadap pada dua lokasi perkebunan karet

Table 3. Characteristics of tappers on two location of rubber enterprises

\begin{tabular}{|c|c|c|c|c|c|c|}
\hline \multirow{2}{*}{ No. } & \multirow{2}{*}{$\begin{array}{l}\text { Uraian } \\
\text { Description }\end{array}$} & & \multicolumn{2}{|c|}{ PB A } & \multicolumn{2}{|c|}{ PB B } \\
\hline & & & KHT & KHL & KHT & KHL \\
\hline 1 & $\begin{array}{l}\text { Usia (Tahun): } \\
\text { Age (yr): }\end{array}$ & $\begin{array}{l}\text { Selang usia } \\
\text { Rata-rata }\end{array}$ & $\begin{array}{c}32-53 \\
(44)\end{array}$ & $\begin{array}{c}24-54 \\
(38)\end{array}$ & $\begin{array}{c}28-41 \\
(34)\end{array}$ & $\begin{array}{c}23-53 \\
(34)\end{array}$ \\
\hline
\end{tabular}

2 Ada pekerjaan lain (\%)

Education (\%)

SD

$\begin{array}{cc}54 & 32 \\ 46 & 24 \\ 0 & 44 \\ 100 & 100\end{array}$

SMP

SMA

Jumlah

$4 \quad$ Masa kerja (\%)

$$
\begin{aligned}
& \text { Working period (\%) } \\
& <5 \text { tahun }(y r) \\
& >5-10 \text { tahun }(y r) \\
& >10-20 \text { tahun }(y r) \\
& >20 \text { tahun (yr) } \\
& \text { Jumlah }
\end{aligned}
$$

$\begin{array}{cccc}15 \% & 60 \% & 45 \% & 66 \% \\ 8 \% & 16 \% & 50 \% & 29 \% \\ 77 \% & 8 \% & 5 \% & 5 \% \\ 0 & 16 \% & 0 & 0 \\ 100 & 100 & 100 & 100\end{array}$

Rata-rata masa kerja (th)

$14 \quad 8$

4 
lingkungan serta sosial budaya. Dalam penelitian ini, tingkat kesejahteraan rumah tangga penyadap dianalisis dengan hanya menggunakan indikator kepemilikan aset, tingkat pendapatan dan pengeluaran / konsumsi rumah tangga, tingkat pendidikan anak dan tingkat ketahanan pangan.

\section{Kepemilikan aset}

Kepemilikan aset yang diamati dalam penelitian ini meliputi kebun/ladang, rumah, televisi (TV), ternak, dan sepeda motor. Tabel 4 memperlihatkan perbedaan tingkat kesejahteraan antara tenaga penyadap di PB A dengan tenaga penyadap di $\mathrm{PB} B$ sekaligus memperlihatkan adanya perbedaan tingkat kesejahteraan antara tenaga penyadap berstatus KHT dengan tenaga penyadap berstatus KHL. Sebanyak $33 \%$ penyadap KHT dan $23 \%$ penyadap KHL di PB A memiliki kebun/ladang dengan luas rata-rata mencapai 2 - 7 rantai $(800-2.800$ $\mathrm{m}^{2}$ ). Kebun tersebut biasanya digunakan untuk berladang padi, singkong, dan palawija, dan hasilnya untuk dikonsumsi sendiri. Beberapa diantaranya bahkan digunakan untuk menanam karet atau bibit karet yang hasilnya digunakan untuk keperluan rumah tangganya sendiri. Sementara di PB B, tidak ada satupun penyadap yang memiliki kebun/ladang sendiri.

Rumah telah dimiliki oleh $67 \%$ penyadap KHT dan $8 \%$ penyadap KHL di PB A. Umumnya penyadap tersebut merupakan penyadap yang telah lama bekerja dan menyadari pentingnya kepemilikan rumah saat memasuki usia pensiun. Demikian halnya di $\mathrm{PB} \mathrm{B}$, meski lebih sedikit, sebanyak $17 \%$ penyadap KHT dan $4 \%$ penyadap KHL memiliki rumah yang dipersiapkan untuk memasuki masa pensiun. Selebihnya baik di PB A maupun $\mathrm{PB} B$ masih tinggal di perumahan yang disediakan oleh kebun.

Seluruh penyadap KHT dan sebagian (54\%) penyadap KHL di PB A telah memiliki TV, sementara di PB B hanya $42 \%$ penyadap KHT dan $21 \%$ penyadap KHL yang telah memiliki TV. Sebanyak $17 \%$ penyadap KHT dan $15 \%$ penyadap KHL di PB A memiliki ternak, sementara tidak satupun penyadap di PB B yang memiliki ternak. Adapun dengan sepeda motor, seluruh penyadap KHT dan sebagian besar (85\%) penyadap KHL di PB A telah memiliki sepeda motor, sementara di PB B hanya $83 \%$ penyadap KHT dan $63 \%$ penyadap KHL di PB B yang telah memiliki sepeda motor.

Kelima atribut (kebun/ladang, rumah, TV, ternak, dan sepeda motor) dari indikator kepemilikan aset yang telah diuraikan di atas jelas memberikan gambaran akan adanya perbedaan tingkat kesejahteraan penyadap antara perkebunan di PB A dan perkebunan di PB B. Berikut Tabel 3 mempelihatkan persentase penyadap berdasarkan kepemilikan aset sebagaimana telah diuraikan sebelumnya.

\section{Tingkat pendidikan anak}

Kajian terhadap pendidikan anak penyadap dilakukan terhadap sampel penyadap yang telah berkeluarga. Secara umum, setiap keluarga penyadap memiliki rata-rata $1-3$ orang anak. Dilihat dari tingkat pendidikan anak, terlihat bahwa seluruh anak telah mengecap pendidikan, beberapa diantara anak tersebut telah menyelesaikan pendidikan setingkat SMA dan bahkan ada yang sedang menempuh pendidikan di perguruan tinggi. Hampir tidak ditemukan anak penyadap yang tidak mengecap pendidikan. Beberapa diantara anak penyadap masih belum memperoleh pendidikan dikarenakan memang belum memasuki usia sekolah. Hal ini juga terkait dengan usia penyadap yang umumnya tergolong muda dan baru memasuki kehidupan berumah tangga.

Dalam Nancy (1997) dinyatakan bahwa dengan tingkat pendidikan anak yang lebih baik, penyadap tidak lagi menginginkan agar anaknya bekerja sebagai penyadap, tetapi berharap agar anaknya memperoleh pekerjaan yang lebih baik dari orang tuanya. Demikian halnya dalam penelitian ini, seluruh sampel penyadap menyatakan harapannya agar anak-anak mereka tidak bekerja sebagai penyadap, tetapi memperoleh pekerjaan yang lebih baik dari profesi penyadap yang notabene dirasakan sebagai pekerjaan rendahan di kebun. Uraian di atas memperlihatkan bahwa profesi sebagai penyadap masih dianggap kurang menarik. Menyadap merupakan pilihan terakhir. Dengan kata lain, preferensi penyadap terhadap profesinya lebih rendah dibandingkan alternatif profesi atau pekerjaan lain yang dapat memberikan jaminan hidup yang lebih baik saat ini. 
Tabel 4. Kepemilikan aset penyadap pada dua lokasi perkebunan karet Table 4. Asset ownership on two location of rubber enterprises

\begin{tabular}{llrrrrrr}
\hline Kepemilikan aset & & \multicolumn{3}{c}{ PB A } & & \multicolumn{2}{c}{ PB B } \\
\cline { 3 - 4 } \cline { 6 - 8 } Asset ownership & & KHT & KHL & & KHT & KHL \\
\hline Kebun/Ladang (Land) & $(\%)$ & & 33 & 23 & & 0 & 0 \\
Rumah (Home) & $(\%)$ & 67 & 8 & & 17 & 4 \\
TV(TV) & $(\%)$ & 100 & 54 & & 42 & 21 \\
Ternak (Livestock) & $(\%)$ & 17 & 15 & & 0 & 0 \\
Sepeda motor (Motorcycle) & $(\%)$ & 100 & 85 & & 83 & 63 \\
\hline
\end{tabular}

Tabel 5. Tingkat pendidikan anak penyadap pada dua lokasi perkebunan karet (\%) Table 5. Education level of tappers children on two location of rubber enterprises (\%)

\begin{tabular}{|c|c|c|c|c|c|c|c|}
\hline \multicolumn{8}{|c|}{$\begin{array}{l}\text { Persentase tingkat pendidikan anak penyadap } \\
\text { Percentage of education level of tappers children }\end{array}$} \\
\hline $\begin{array}{c}\text { Tipe } \\
\text { perkebunan } \\
\text { Estates }\end{array}$ & $\begin{array}{l}\text { Jumlah } \\
\text { Anak } \\
\text { Number } \\
\text { of } \\
\text { Children }\end{array}$ & $\begin{array}{c}\text { Sekolah } \\
\text { Dasar } \\
\text { Primary } \\
\text { School }\end{array}$ & $\begin{array}{c}\text { Sekolah } \\
\text { Menengah } \\
\text { Pertama } \\
\\
\text { Secondary } \\
\text { High } \\
\text { School }\end{array}$ & $\begin{array}{c}\text { Sekolah } \\
\text { Menengah } \\
\text { Atas } \\
\text { Senior } \\
\text { High } \\
\text { School }\end{array}$ & $\begin{array}{c}\text { Perguruan } \\
\text { Tinggi } \\
\text { University }\end{array}$ & $\begin{array}{c}\text { Belum } \\
\text { sekolah } \\
\text { Not yet } \\
\text { schooling }\end{array}$ & Total \\
\hline PB A & & & & & & & \\
\hline - KHT & 2,2 & 38 & 15 & 38 & 8 & 0 & 100 \\
\hline - KHL & 1,7 & 35 & 0 & 0 & 0 & 65 & 100 \\
\hline PB B & & & & & & & \\
\hline - KHT & 2 & 42 & 13 & 8 & 0 & 38 & 100 \\
\hline - KHL & 2,3 & 37 & 3 & 0 & 0 & 60 & 100 \\
\hline
\end{tabular}

\section{Tingkat pendapatan dan pengeluaran rumah tangga penyadap}

Pendapatan yang diterima oleh penyadap meliputi gaji pokok, premi, dan insentif atau bonus. Pembayaran gaji pokok, premi, dan insentif pada kedua kebun dilakukan setiap bulan sekali. Jumlah pendapatan premi dapat berbeda-beda setiap bulan tergantung perolehan produksi yang didapat oleh penyadap. Jika di PBS A pendapatan lain umumnya didapat oleh penyadap dari pekerjaan sampingan, di PBS $B$ pendapatan lain umumnya didapat oleh penyadap dari kontribusi isteri penyadap yang ikut membantu keuangan keluarga dari aktivitas buruh borongan di kebun yang sama. Pendapatan rata-rata penyadap secara umum mencapai Rp 2,2 juta-Rp 2,4 juta (Tabel 6).

Pengeluaran terbesar rumahtangga penyadap secara umum berasal dari kebutuhan pokok (32\% - 34\%). Menyusul pengeluaran untuk kebutuhan pendidikan
$(11 \%-16 \%)$, transportasi $(7 \%-9 \%)$, dan tabungan (4\% - 20\%). Adapun kebutuhan lain-lain yang mencapai $23 \%-37 \%$ dari pengeluaran rumah tangga umumnya digunakan untuk keperluan cicilan sepeda motor atau hutang jasa simpan pinjam koperasi. Kemampuan mengalokasikan pendapatan yang lebih besar justru terlihat pada penyadap KHL di PB B. Hal ini disinyalir akibat secara umum penyadap KHL di PB B baru memasuki usia pernikahan muda dengan tingkat pendidikan anak yang relatif masih rendah bahkan belum sekolah sehingga pengeluaran untuk kebutuhan pokok dan pendidikan anak menjadi lebih sedikit.

\section{Tingkat Ketahanan Pangan Keluarga Penyadap}

Indikator kesejahteraan rumahtangga dapat juga dilihat dari tingkat ketahanan pangan rumahtangga itu sendiri. Salah satu diantara karakteristik rumahtangga rawan pangan sebagaimana 
didefinisikan Maxwell et al. dalam Ariningsih (2008) adalah pangsa pengeluaran pangan $>60 \%$ dari total pengeluaran rumahtangga. Penelitian yang sama oleh Nancy et al. pada tahun 1997 memperlihatkan adanya kecenderungan terjadinya rawan pangan pada rumahtangga penyadap di perkebunan karet, dimana proporsi pengeluaran pangan secara agregat mencapai 65,75\%. Kondisi rawan pangan terutama terjadi pada perkebunan dengan lokasi yang berada jauh dari kota (terpencil) dimana proporsi pengeluaran pangan rumah tangga penyadap mencapai $79,00 \%$.

Tidak demikian halnya dengan keragaan rumahtangga penyadap yang terlihat pada penelitian kali ini, dimana berdasarkan Tabel 6 dapat dilihat bahwa secara agregat kondisi rumah tangga penyadap di perkebunan karet sampel masih tergolong berkecukupan pangan dengan proporsi pengeluaran pangan yang hanya mencapai 38,25\%, sehingga jika dikaitkan dengan penelitian terdahulu oleh Nancy (1997) maka terlihat adanya peningkatan kesejahteraan rumah tangga penyadap saat ini. Hanya saja perlu dianalisis lebih jauh distribusi pengeluaran pangan berdasarkan jenis konsumsi pangan dan kecukupan gizi dan energi. Dengan kata lain rendahnya tingkat kesejahteraan penyadap belum menyentuh pada level kerawanan pangan.

\section{KESIMPULAN DAN SARAN}

1. Meski memiliki rata-rata jumlah pendapatan pokok yang tidak berbeda signifikan bahkan cenderung lebih rendah, tingkat kesejahteraan rumahtangga penyadap di PB A dapat dikategorikan lebih baik dari rumahtangga penyadap di PB $\mathrm{B}$. Hal ini ditunjukkan oleh kepemilikan aset dan tingkat pendidikan anak yang lebih baik. Penyadap di PB A banyak yang telah memiliki rumah pribadi serta beberapa diantaranya juga memiliki kebun/ladang dan ternak sendiri. Kemudahan memperoleh akses pendidikan, pusat bisnis dan perdagangan, serta pusatpusat layanan pemerintah lainnya akibat lokasi kebun yang berada dekat dengan kota menjadi alasan perbedaan tingkat kesejahteraan yang dimiliki diantara kedua kelompok penyadap.

Tabel 6. Tingkat pendapatan dan pengeluaran rumahtangga penyadap pada dua lokasi perkebunan karet

Table 6. Rate of family income and expenditure on two location of rubber enterprises

\begin{tabular}{|c|c|c|c|c|c|c|c|c|}
\hline \multirow{2}{*}{$\begin{array}{c}\text { Uraian } \\
\text { Description }\end{array}$} & \multicolumn{3}{|c|}{$\mathrm{PB} \mathrm{A}$} & \multicolumn{4}{|c|}{$\mathrm{PB} B$} & \multirow[b]{2}{*}{$(\%)$} \\
\hline & $\begin{array}{c}\text { KHT } \\
\text { (Ribu } \\
\text { Rp/tahun) }\end{array}$ & $(\%)$ & $\begin{array}{c}\text { KHL } \\
\text { (Ribu } \\
\text { Rp/tahun) }\end{array}$ & $(\%)$ & $\begin{array}{c}\text { KHT } \\
\text { (Ribu } \\
\text { Rp/tahun) }\end{array}$ & $(\%)$ & $\begin{array}{c}\text { KHL } \\
\text { (Ribu } \\
\text { Rp/tahun) }\end{array}$ & \\
\hline \multicolumn{9}{|l|}{$\begin{array}{l}\text { Pendapatan } \\
\text { Income }\end{array}$} \\
\hline - Gaji pokok (Basic wage) & 1.500 & $(68)^{a}$ & 1.800 & $(78)^{\mathrm{b}}$ & 1.700 & $(70)^{\mathrm{b}}$ & 1.850 & $(78)^{\mathrm{b}}$ \\
\hline $\begin{array}{l}\text { - Premi (Premium) } \\
\text { - Insentif/Bonus } \\
\text { (Incentive/Bonus) }\end{array}$ & $\begin{array}{l}195 \\
250\end{array}$ & $\begin{array}{r}(9) \\
(11)\end{array}$ & $\begin{array}{c}165 \\
-\end{array}$ & $\begin{array}{l}(7) \\
(0)\end{array}$ & $\begin{array}{l}170 \\
200\end{array}$ & $\begin{array}{l}(7) \\
(8)\end{array}$ & $\begin{array}{c}150 \\
-\end{array}$ & $\begin{array}{l}(6) \\
(0)\end{array}$ \\
\hline Subtotal & 1.945 & $(88)$ & 1.965 & $(85)$ & 2.070 & (85) & 2.000 & (85) \\
\hline - Lainnya (Others) & 270 & (12) & 340 & $(15)$ & 364.5 & (15) & 360 & (15) \\
\hline - Total & 2.215 & $(100)$ & 2.305 & $(100)$ & 2.434 .5 & $(100)$ & 2.360 & $(100)$ \\
\hline \multicolumn{9}{|l|}{ Pengeluaran } \\
\hline $\begin{array}{l}\text { Expenditure } \\
\text { - Kebutuhan pokok } \\
\text { (Basic need) }\end{array}$ & 970 & (44) & 900 & (39) & 920 & (38) & 750 & (32) \\
\hline $\begin{array}{l}\text { - Pendidikan } \\
\text { (Education) }\end{array}$ & 350 & (16) & 250 & $(11)$ & 400 & $(16)$ & 250. & $(11)$ \\
\hline $\begin{array}{l}\text { - Transportasi } \\
\text { (Transportation) }\end{array}$ & 157.5 & (7) & 210 & (9) & 181 & (7) & 167 & (7) \\
\hline - Tabungan (Saving) & 230 & (10) & 100 & (4) & 170 & (7) & 475 & (20) \\
\hline - Lain-lain (Others) & 507.5 & (23) & 845 & $(37)$ & 763.5 & $(31)$ & 718 & (30) \\
\hline
\end{tabular}

Catatan : Pendapatan KHT belum termasuk tunjangan sosial berupa jaminan kesehatan dan ketenagakerjaan.

Note: PDL income not included socio incentive namely healthy and working assurance.

Angka-angka yang diikuti oleh huruf yang berbeda pada baris yang sama berbeda nyata pada taraf $5 \%$.

Number followed by the different letter on same row were significantly different at $5 \%$ significant level. 
2. Rasio luas lahan dan tenaga kerja yang tinggi di kebun PB B mengindikasikan adanya masalah tenaga kerja. Tingkat keluar masuk (turn-over) tenaga penyadap yang cenderung tinggi memperkuat adanya problem kepuasan penyadap terhadap aspek kesejahteraan. Terbatasnya akses memperoleh pelayanan pendidikan, pelayanan bisnis dan perdagangan, serta pusat-pusat pelayanan pemerintah lainnya menjadi salah satu penyebab lambannya perbaikan kesejahteraan penyadap di PB B. Oleh karena itu perlu bagi manajemen kebun untuk menyediakan sarana transportasi agar penyadap dapat menjangkau kebutuhan tersebut serta menyediakan kebutuhan-kebutuhan pokok melalui peran dan fungsi koperasi.

3. Dibandingkan dengan hasil penelitian terdahulu oleh Nancy (1997), berdasarkan parameter tingkat ketahanan pangan, maka terlihat adanya peningkatan kesejahteraan rumahtangga penyadap di perkebunan karet saat ini. Secara agregat kondisi rumahtangga penyadap di kedua tipe perkebunan karet sampel masih tergolong berkecukupan pangan dengan proporsi pengeluaran pangan yang hanya mencapai 38,25\% dari maksimal kategori rawan pangan sebesar 60,00\%. Dengan kata lain, rendahnya tingkat kesejahteraan rumahtangga penyadap saat ini tidak lagi menyentuh level kerawanan pangan sebagaimana yang terjadi dan terlihat pada hasil penelitian terdahulu.

\section{UCAPAN TERIMA KASIH}

Ucapan terima kasih kami tujukan kepada Universitas Medan Area yang telah membiayai penelitian ini selama 2 (dua) tahun melalui dana penelitian kerjasama (KSR) tahun anggaran 2013-2014. Ucapan terima kasih juga disampaikan kepada segenap pimpinan perusahaan perkebunan A (PB A) dan B (PB B) beserta jajaran (manager, askep, asisten, mandor, dan penyadap) yang telah mendukung pelaksanaan kegiatan penelitian ini, serta kepada pihak yang tidak dapat kami sebutkan satu persatu.

\section{DAFTAR PUSTAKA}

Ariningsih, E. dan Rachman, P. S. 2008. Strategi Peningkatan Ketahanan Pangan Rumah Tangga Rawan Pangan. Jurnal Analisis Kebijakan Pertanian 6(3) : $239-255$.

Badan Pusat Statistik. 2011. Statistik Indonesia. BPS, Jakarta.

Nancy, C., C. Anwar., U. Junaedi., dan S. Hendratno. 1997. Ketersediaan dan Kesejahteraan Tenaga Penyadap di Perkebunan Karet (Studi Kasus di Beberapa Perkebunan Besar di Sumatera Selatan dan Lampung). Jurnal Penelitian Karet 15(1): 23-41.

Ravianto, J. 1985. Labor Productivity. Lembaga Sarana Informasi Usaha dan Produktivitas, Jakarta.

Spillane, J. J. 1989. Komoditi Karet : Peranannya Dalam Perekonomian Indonesia. Kanisius, Yogyakarta.

Santoso, B. dan Basuki. 1991. Manajemen Panen Tanaman Karet di Perkebunan. Kumpulan Makalah Lokakarya Karet 1991. Balai Penelitian Sungei Putih, Medan.

Simatupang, P., N. Syafa'at., K. M. Noekman., A. Syam., S. K. Dermoredjo., dan B. Santoso. 2001. Kelayakan Pertanian Sebagai Sektor Andalan Pembangunan Ekonomi Nasional. Forum Diskusi Pembangunan Pertanian. Bogor, 10 Mei.

Siregar, M., M. Simangunsong., dan M. Jamian. 1984. Masalah Tenaga Kerja Penyadap di Perkebunan Karet. Kumpulan Makalah Lokakarya Karet 1984 PN/ PT Perkebunan Wilayah I dan P4TM. Balai Penelitian Sungei Putih, Medan.

Suryana, A. 2001. Tantangan dan Kebijakan Ketahanan Pangan. Prosiding Seminar Nasional Pemberdayaan Masyarakat untuk Mencapai Ketahanan Pangan dan Pemulihan Ekonomi. Jakarta, 29 Maret. 